\title{
Qualidade do ar em ambientes internos hospitalares: estudo de caso e análise crítica dos padrões atuais
}

\section{Indoor air quality in hospitals: a case study and a critical review of current standards}

\section{Marina Eller Quadros}

Mestre em Engenharia Ambiental pela Universidade Federal de Santa Catarina (UFSC). Doutoranda em Engenharia Civil e Ambiental pela Virginia

Polytechnic Institute and State University

\author{
Henrique de Melo Lisboa
}

Doutor em Poluição Atmosférica pela de Pau/École des Mines d'Alès. Professor-associado do Departamento de Engenharia Sanitária e Ambiental da UFSC

\section{Vetúria Lopes de Oliveira}

Doutora em Biologia e Fisiologia Vegetal pela Université de Nancy I. Professora Titular do Departamento de Microbiologia e Parasitologia da UFSC

\section{Waldir Nagel Schirmer}

Doutor em Poluição Atmosférica pela UFSC. Professor adjunto do Departamento de Engenharia Ambiental da Universidade Estadual do Centro-oeste (Unicentro)

\section{Resumo}

O objetivo deste trabalho foi avaliar a qualidade do ar em três categorias de ambientes hospitalares: unidade de terapia intensiva (UTI) adulto, UTI neonatal (UTN) e centro cirúrgico de um hospital em Florianópolis, Brasil. Avaliaram-se a concentração de dióxido de carbono, a vazão e renovação de ar nas salas do centro cirúrgico. A concentração de bioaerossóis foi estimada em um dia de avaliação para cada ambiente. Não se observou relação entre a concentração de bioaerossóis e o tempo de uso das salas de cirurgia. A concentração média de bioaerossóis foi de 231 UFC. $\mathrm{m}^{-3}$ para fungos e de 187 UFC. $\mathrm{m}^{-3}$ para bactérias. Os ambientes avaliados atendiam aos valores recomendados pela legislação vigente. Os resultados permitiram avaliar criticamente essa legislação e apresentar sugestões para estabelecimento de uma resolução específica para ambientes hospitalares no Brasil.

Palavras-chave: ambiente hospitalar; bioaerossol; dióxido de carbono; qualidade do ar de interiores.

\section{Abstract}

The objective of this paper was to evaluate the air quality in three indoor hospital environments: a neonatal intensive care unit (ICU), an adult ICU and a surgical ward of a hospital in Florianópolis, Brazil. Carbon dioxide concentrations, exchange air flow rates as well as fungi and bacteria concentrations were measured in these rooms. Bioaerosol concentrations were evaluated throughout one-work day for each operating room. No relationship was observed between bioaerosol concentration and the period of use in the surgical ward. Average bioaerosol concentrations were of $231 \mathrm{UFC} . \mathrm{m}^{-3}$ for filamentous fungi and 187 UFC. $\mathrm{m}^{-3}$ for bacteria. All environments evaluated were, overall, in compliance with current legislations. Results allowed a critical review of the present regulations and suggestions for the establishment of a specific regulation for hospital environments in Brazil.

Keywords: hospital environment; bioaerosol; carbon dioxide; indoor air quality.

\section{Introdução}

Entende-se por ar de interiores aquele de áreas não industriais, como habitações, escritórios, escolas e hospitais (WANG; ANG; TADE, 2007). O estudo de sua qualidade é importante para garantir saúde aos ocupantes dos diferentes edifícios, bem como o ótimo desempenho de suas atividades (GIODA; AQUINO NETO, 2003). A preocupação com a qualidade do ar de interiores (QAI) surgiu principalmente com a tendência em se construirem edifícios selados por motivos estéticos, controle de ruído e mesmo climatização, o que acabou provocando um aumento nos casos de problemas relacionados à qualidade do ar de tais ambientes (GIODA, 2003; LEE; AWBI, 2004)

O interesse por estudos sobre a QAI surgiu após a descoberta de que a diminuição das taxas de troca de ar nesses ambientes era a grande responsável pelo aumento da concentração de poluentes 
biológicos e não biológicos. Essa preocupação se justifica uma vez que grande parte das pessoas passa a maior parte do seu tempo dentro desses edifícios e, consequentemente, exposta aos seus poluentes (BRICKUS; AQUINO NETO, 1999; LEE; AWBI, 2004; TURIEL et al, 1983).

A qualidade inadequada do ar em ambientes internos está associada à perda de produtividade e ao absenteísmo no ambiente de trabalho (JONES, 1999; SPENGLER, 2004). Portnoy, Flappan e Barnes (2001) associam o aumento da incidência e da prevalência mundial de asma à exposição a poluentes do ar de interiores. A Organização Mundial de Saúde (OMS) contabilizou a contribuição de uma variedade de fatores de riscos a doenças e determinou que a poluição do ar de interiores é o oitavo mais importante fator de risco, responsável por 2,7\% dos casos de doenças no mundo (WHO, 2008).

No caso específico de uma unidade de saúde, a qualidade do ar pode exercer uma influência direta e significativa na velocidade de recuperação dos pacientes e na ocorrência de infecções hospitalares. Em unidades de atendimento de portadores de câncer e doenças imunodepressoras, como a síndrome da imunodeficiência adquirida (AIDS), estudos desta natureza ganham ainda mais importância, pois os usuários dessas unidades encontram-se com o sistema imunológico comprometido.

Existe um número limitado de trabalhos publicados atualmente sobre a qualidade do ar em ambientes hospitalares em termos dos aspectos químicos e microbiológicos do ar, especialmente trabalhos que utilizaram métodos de amostragem que permitem a quantificação de micro-organismos por volume de ar amostrado. Os trabalhos de Sautour et al (2009) e Srikanth, Sudharsanam e Steinberg (2008) são alguns exemplos de trabalhos que realizaram este tipo de estudo. Sautour et al (2009) realizaram um levantamento da concentração de fungos no ar e apontaram a necessidade de se fazer um controle restrito da presença destes micro-organismos nas áreas de hematologia, tratamento de câncer e transplantados.

Diversos trabalhos descrevem a realização de questionários para avaliação da qualidade do ponto de vista ocupacional (NORDSTROM; NORBACK; AKSELSSON, 1995; HELLGREN; REIJULA, 2006; DESCALAKI et al, 2009). Outros descrevem a modelagem computacional da dinâmica dos fluidos dentro de salas de cirurgia. Neste trabalho, a qualidade do ar é descrita em termos da temperatura, umidade relativa e velocidade do ar, além da concentração de contaminantes (HO; ROSARIO; RAHMAN, 2009). No Brasil, alguns trabalhos já foram realizados abordando a microbiota do ar em ambientes hospitalares (NUNES, 2005; MOBIN; SALMITO, 2006). Nunes (2005) também cita a necessidade da criação de uma legislação específica para unidades de saúde; entretanto, sugestões específicas não são feitas sobre os padrões a serem adotados.

Existem, no Brasil, normas reguladoras da qualidade do ar, em especial aquelas estabelecidas pela Anvisa (Agência Nacional de Vigilância Sanitária). Uma destas é a Resolução 9, de 16 de janeiro de 2003, que estabelece padrões de referência de qualidade do ar de interiores, em ambientes climatizados artificialmente de uso público e coletivo (BRASIL, 2003). As unidades de saúde se enquadram no escopo desta resolução. Em 2003, a Anvisa realizou uma consulta pública, denominada CP n 109, para a introdução de uma resolução específica para a qualidade do ar em unidades de saúde, sem que até a presente data ela tenha sido publicada (NUNES, 2005)

O objetivo deste trabalho foi avaliar a qualidade do ar de interiores em três categorias de ambientes hospitalares: unidade de terapia intensiva neonatal (UTN), unidade de terapia intensiva adulto (UTI) e centro cirúrgico de um hospital público de Florianópolis (SC), visando a estabelecer a relação entre o uso dos ambientes e a qualidade do ar de interiores e realizar uma análise crítica da legislação brasileira atual específica para ambientes internos.

\section{Metodologia}

Os locais avaliados foram estrategicamente selecionados em função do estado de saúde comprometido ou enfraquecido dos pacientes, o que induz à infecção hospitalar. Assim, foram realizadas avaliações da qualidade do ar em três categorias de ambientes: UTI neonatal, UTI adulto e duas salas do centro cirúrgico do hospital. Todas as avaliações aconteceram durante o verão, no mês de março de 2008

Localizada dentro da unidade de neonatologia do hospital, a UTI neonatal tem capacidade para seis leitos, e recebe todos os pacientes recém-nascidos do hospital em estado crítico, necessitando de observação e cuidados intensivos. A sala possui $45 \mathrm{~m}^{2}$ de área. O sistema de ar condicionado foi instalado em 1982 e, na data da amostragem, contava com um filtro grosso (classe G3), dois filtros-bolsa (classe F7) e dois filtros-absolutos (classe A3, ou HEPA), em paralelo. A UTI neonatal foi avaliada em medições pontuais isoladas, em dois dias distintos, uma no período matutino e outra no período vespertino. O ambiente possuía uma ocupação de até cinco pessoas no ambiente durante as amostragens, incluindo os pais e a equipe médica. Havia entre dois e cinco bebês nas incubadoras desta sala.

A UTI adulto havia sido inaugurada no mesmo mês em que as amostras foram coletadas. Apesar de possuir 20 vagas, possuía apenas sete leitos ocupados na época das amostragens, pois os demais ainda não haviam sido ativados. Como esta área foi instalada em um bloco recém-construído do hospital, o sistema de ventilação também era de instalação recente. O sistema é do tipo fan-coil e possui termostato e controles de temperatura e umidade no próprio ambiente. Este sistema também possuía um filtro-grosso (classe G3), dois filtros-bolsa (classe F7) e dois filtros-absolutos (classe A3, ou HEPA), em paralelo.

Assim como foi realizado na UTI neonatal, a UTI adulto também foi avaliada em medições pontuais isoladas, em dois dias distintos, 
uma no período matutino e outra no período vespertino. A ocupação na UTI adulto era muito variada (entre 5 e 30 pessoas, incluindo os pacientes e equipe médica) e o ambiente muito grande (mais de 50 $\mathrm{m}^{2}$ de área) com diversas divisórias e balcões entre cada leito, o que dificultou uma compreensão do comportamento das correntes de ar nesse ambiente.

O centro cirúrgico do hospital possui cinco salas de cirurgia e uma sala de recuperação pós-cirúrgica. Em cada sala são realizadas cirurgias agendadas ou emergenciais. As cirurgias agendadas se iniciam às 8 horas da manhã e, à medida que são finalizadas, cada sala é limpa individualmente e recebe novas cirurgias agendadas ou emergenciais. As atividades agendadas são finalizadas ao final da tarde, em torno das 19 horas. Após este horário, somente cirurgias emergenciais são realizadas. Assim, o centro cirúrgico funciona de forma ininterrupta, 24 horas por dia.

Em cada sala de cirurgia existe, além do sistema de ar condicionado individual, uma unidade de ar condicionado de janela, que foi mantida desligada durante as amostragens. O sistema de ar condicionado também é do tipo fan-coil, havendo unidades independentes para cada sala de cirurgia. Cada sistema possuía um filtro-grosso (classe G3), um filtro-bolsa (classe F7) e dois filtros-absolutos (classe A3, ou HEPA). As medições foram feitas nas salas de cirurgia 1 (de 27,5 $\mathrm{m}^{2}$ de área) e 3 (de 22,5 $\mathrm{m}^{2}$ de área). Cada sala foi avaliada no decorrer de um dia normal de funcionamento, do início ao fim do período de sua utilização.

As salas de cirurgia são menores do que as da UTI, não possuem divisórias ou balcões e apresentam, também, menor trânsito de pessoas e equipamentos ou abertura de portas no decorrer do dia. Nesse caso, avaliou-se o comportamento da qualidade do ar no decorrer do dia devido às suas dimensões físicas e, também, a forma de utilização dessas salas.

Para fins comparativos, coletaram-se amostras em um ponto externo ao hospital, em uma claraboia no quinto andar do prédio, pelo lado externo, que era o local mais próximo de onde é feita a captação de ar para os sistemas fan-coil de ar condicionado central.

\section{Concentração de dióxido de carbono $\left(\mathrm{CO}_{2}\right)$, temperatura e umidade relativa do ar}

Foram realizadas medições da concentração de dióxido de carbono, utilizando-se um aparelho portátil de leitura direta por meio de sensor infravermelho não dispersivo (modelo CO-2, marca Instrutherm). Esse aparelho é capaz de realizar medições de temperatura em bulbo seco e bulbo úmido, fornecendo o valor da umidade relativa do ar, além de seguir as recomendações técnicas para faixa de leitura e exatidão estabelecidas pela resolução RE nº 9 da ANVISA (BRASIL, 2003). Dados de concentração de $\mathrm{CO}_{2}$, temperatura e umidade relativa do ar foram coletados simultaneamente a cada um minuto e armazenados na memória do aparelho.
No momento dessas medições, foram feitas anotações em relação ao grau de ocupação destas salas para que a concentração de $\mathrm{CO}_{2}$ pudesse ser comparada a esse número. Utilizou-se o programa Excel para o cálculo de retas de regressão e plotagem dos resultados.

Posteriormente, foram utilizados os métodos estatísticos recomendados por Barbetta, Reis e Bornia (2008) para a determinação do intervalo de $95 \%$ de confiança para a média (bicaudal). Considerouse que a distribuição dos dados possa ser aproximada pela distribuição $t$ de Student, e que o tamanho da população seja desconhecido ou muito superior ao tamanho da amostra $(\mathrm{N}>>n)$.

\section{Velocidade e renovação do ar nas salas do centro cirúrgico}

As medições das velocidades das correntes de ar foram feitas em posição central, a 1,50 m de altura do piso de cada ambiente estudado. Foram tomadas medições em todas as direções e o valor máximo foi anotado.

Nas duas salas do centro cirúrgico, foi medida a vazão de insuflamento de ar, através da medição da velocidade do ar na saída dos insufladores de cada sala. Utilizou-se um anemômetro a fio quente (marca AIRFLOW ${ }^{\circledR}$, modelo TA45). Foram eleitos dez pontos ao longo de cada insuflador (de 2,0 × 0,15 m), seguindo-se as recomendações do método Log-Tchebycheff, que indica que a distância entre os pontos de medição não deve exceder $20 \mathrm{~cm}$ para dutos com largura superior a 1,40 m (ZHANG, 2004).

A razão entre a vazão de insuflamento e o volume de cada sala do centro cirúrgico foi calculada para determinar a taxa de renovação de ar nesses ambientes (em trocas de ar por hora). De posse da vazão de insuflamento e da ocupação máxima em cada sala, também foi possível calcular a taxa de renovação de ar em termos da vazão de ar disponível para cada ocupante $\left(\mathrm{m}^{3} \cdot \mathrm{h}^{-1}\right.$. pessoa ${ }^{-1}$, por exemplo).

Foram ainda utilizados os dados de projeto do sistema de ventilação de ar. A vazão de projeto de cada sistema é a mesma, de 2.516 $\mathrm{m}^{3} \cdot \mathrm{h}^{-1}$, dos quais $460 \mathrm{~m}^{3} \cdot \mathrm{h}^{-1}$ vêm do ar externo, o que dá uma taxa de recirculação de aproximadamente $82 \%$.

\section{Amostragem de fungos e bactérias no ar}

Foram utilizados como meios de cultura o Ágar Sabouraud dextrose (ASD) 4\% e Ágar Sangue de Carneiro 5\% (ASC) para o cultivo de fungos e bactérias, respectivamente. Esses meios foram vertidos em placas de Petri descartáveis estéreis sob condições assépticas de fluxo laminar. Depois de preparadas, as placas foram seladas com filme de PVC e acondicionadas em sacos plásticos selados para serem levadas a campo. As placas contendo ASC foram mantidas em geladeira até o momento do uso e as placas com ASD foram mantidas sob temperatura ambiente. 
Fez-se uso de um amostrador de ar por impactação através de peneiras, também conhecido como amostrador de Andersen, de um estágio (marca SKC, modelo BIOSTAGE 1). Em cada ponto de amostragem, foram coletados $280 \mathrm{~L}$ de ar, com a vazão mantida fixa em 28,0 L.min ${ }^{-1}$, durante dez minutos. Cada amostragem foi feita através da coleta de, no mínimo, duas placas de Petri subsequentes com o mesmo tipo de meio de cultura.

A peça de aço inox onde se acoplou a placa de Petri com meio de cultura foi esterilizada em autoclave, a $121^{\circ} \mathrm{C}$ e 15 psi durante 20 minutos antes de cada dia de amostragem. Entre as amostragens de um mesmo dia, a peça foi desinfetada com algodão embebido em álcool etílico 98 GL e a entrada do amostrador foi selada com algumas camadas de filme de PVC. Entre amostragens consecutivas, passou-se um pedaço de gaze estéril na entrada do amostrador.

\section{Contagem e identificação de fungos e bactérias}

As placas com meio para crescimento de fungos foram incubadas durante dois a três dias à temperatura de $25 \pm 1^{\circ} \mathrm{C}$. Após o período de incubação, procedeu-se à contagem das colônias em cada placa, utilizando-se lupa binocular ( 3 a 30x), efetuando-se duas contagens: a de fungos filamentosos e a de colônias de aparência cremosa (possivelmente leveduras).

Em cada placa, foram selecionadas colônias de fungos filamentosos com aparência macroscópica diferente para isolamento. Tais colônias foram repicadas para tubos contendo $10 \mathrm{~mL}$ de meio de cultura sólido inclinado. Após o crescimento da cultura (dois a três dias), os tubos foram armazenados em geladeira $\left(\mathrm{a} \sim 4^{\circ} \mathrm{C}\right)$.

As placas de fungos foram incubadas durante três dias antes de se proceder à contagem das colônias, que foram expressas em unidades formadoras de colônias por metro cúbico de ar (UFC.m ${ }^{-3}$ ). Depois de isolados, os fungos filamentosos foram submetidos à técnica de microcultivo, para permitir uma melhor observação de suas estruturas reprodutivas e, assim, poder identificá-los (MOBIN; SALMITO, 2006; SILVA FILHO; OLIVEIRA, 2007). Esse procedimento consistiu na inoculação do fungo sobre uma pequena quantidade de meio de cultura sólido (aproximadamente 0,1 mL) colocado na superfície de uma lâmina de vidro para microscopia previamente esterilizada. Após a inoculação, o meio de cultura foi coberto por uma lamínula, também esterilizada, e o sistema foi depositado sobre uma folha de papel de filtro estéril umidificada, no interior de uma placa de Petri estéril. O conjunto foi, então, colocado em incubadora tipo BOD, à temperatura de $25 \pm 1^{\circ} \mathrm{C}$. Assim, foi possível observar toda a cultura em microscopia óptica, sem alterar a integridade das estruturas do fungo.

O período de incubação em microcultivo foi variável de acordo com o tipo de fungo. Algumas culturas já haviam produzido esporos que já se encontravam em fase de germinação em apenas 18 horas de incubação. Em outros casos, foi necessário aguardar mais de sete dias para o aparecimento de esporos. O material observado foi comparado a descrições disponíveis na literatura especializada, como chaves de identificação disponíveis em livros e páginas da Internet (KENDRICK, 1979; WEBSTER, 1985; SILVEIRA, 1995; ALEXOPOULOS; REIS BORNIA, 1996; KONEMAN et al, 1997; KENDRICK, 2000; BENNY, 2008; UA, 2008). Observaram-se as estruturas reprodutivas ou outras estruturas fúngicas características (como clamidósporos), características da hifa (presença ou ausência de septos) e da colônia (formato e textura da colônia, coloração da hifa, dos esporos e da parte inferior da colônia) (KENDRICK, 1979; UA, 2008).

As culturas de bactérias (em ágar sangue de carneiro) foram incubadas durante 36 a 48 horas em estufa a $35 \pm 1^{\circ} \mathrm{C}$, de acordo com a metodologia recomendada por Pasquarella, Pitzurra e Savino (2000). Após o período de incubação, procedeu-se à contagem das colônias em cada placa. O meio de cultura utilizado permitiu a observação a olho nu de zonas de hemólise.

\section{Resultados e discussão}

Os resultados médios da concentração de $\mathrm{CO}_{2}$, temperatura (T), umidade relativa do ar (UR) e velocidade das correntes de ar nos sistemas de ventilação (v) obtidos para cada ambiente são apresentados na Tabela 1, juntamente com o intervalo de 95\% de confiança para

Tabela 1 - Concentração de $\mathrm{CO}_{2}$, temperatura, umidade nos ambientes e velocidade do ar na UTI adulto, UTI neonatal, salas do centro cirúrgico (CC) e ponto externo (PE)

\begin{tabular}{|c|c|c|c|c|c|c|c|c|c|}
\hline \multirow{2}{*}{ Local } & \multirow{2}{*}{ Período } & \multirow{2}{*}{$n^{*}$} & \multicolumn{2}{|c|}{$\mathrm{CO}_{2}(\mathrm{ppm})$} & \multicolumn{2}{|c|}{$\mathrm{T}\left({ }^{\circ} \mathrm{C}\right)$} & \multirow{2}{*}{ UR [\%] } & \multicolumn{2}{|c|}{$v * *$} \\
\hline & & & Média & Máx** & Interna & Ext. & & $n^{*}$ & $(\mathrm{~m} / \mathrm{s})$ \\
\hline UTI & Manhã & 51 & $608 \pm 6$ & 631 & $25,0 \pm 0,0$ & 29 & $64,7 \pm 0,2$ & 5 & 0,16 \\
\hline UTI & Tarde & 21 & $567 \pm 10$ & 635 & $24,6 \pm 0,1$ & 30 & $64,6 \pm 0,2$ & - & - \\
\hline UTN & Manhã & 14 & $484 \pm 3$ & 495 & $28,4 \pm 0,2$ & 34 & $51,1 \pm 0,1$ & 5 & 0,09 \\
\hline UTN & Tarde & 32 & $417 \pm 2$ & 685 & $26,1 \pm 0,1$ & 30 & $51,1 \pm 0,2$ & - & - \\
\hline CC Sala 1 & Integral & 422 & $321 \pm 19$ & 729 & $23,8 \pm 0,1$ & 29 & $59,1 \pm 0,2$ & 5 & 0,15 \\
\hline CC Sala 3 & Integral & 163 & $618 \pm 30$ & 917 & $25,7 \pm 0,1$ & 27 & $51,7 \pm 0,7$ & 5 & 0,10 \\
\hline PE & Manhã & 8 & $321 \pm 46$ & 381 & - & - & $47,6 \pm 2,7$ & - & - \\
\hline Padrões R & & & $<1.000$ & & & & $40-65 \%$ & & $<0,25$ \\
\hline
\end{tabular}

${ }^{*}$ ) Tamanho da amostra (ou número de medições), com dados obtidos a cada um minuto. Os valores representam as médias de cada conjunto de dados juntamente com o seu intervalo de $95 \%$ de confiança. Para as concentrações de $\mathrm{CO}_{2}$ também é apresentado o valor máximo observado.

(**) Valor máximo medido. 
cada média. Também são apresentadas na mesma tabela as temperaturas médias para a cidade de Florianópolis (na coluna "Ext") durante os dias de amostragem.

A velocidade média das correntes do ar, temperatura e umidade do ar, assim como a concentração de dióxido de carbono, atenderam aos requisitos da resolução RE 9 da Anvisa para todos os ambientes estudados, bem como o grau de renovação de ar das salas de cirurgia. Kwoc (2004) cita a temperatura e a umidade relativa, juntamente com a velocidade das correntes de ar, como fatores determinantes no conforto térmico dos usuários de uma edificação. Assim, considerando-se os resultados obtidos, é possível afirmar que as condições de conforto dentro do hospital estavam sendo satisfeitas.

A Figura 1 mostra a relação obtida entre o grau de ocupação das salas de cirurgia e a concentração de $\mathrm{CO}_{2}$, medidos durante cirurgias. Como se pode observar, a concentração de $\mathrm{CO}_{2}$ nas salas de cirurgia apresentou uma relação linear direta com o grau de ocupação das mesmas, evidenciando que os sistemas de ar condicionado são projetados para atender a um determinado grau de ocupação no ambiente.

Também foi realizada uma aferição das vazões insufladas nas salas 1 e 3 do centro cirúrgico. A partir dos dados de projeto de cada sistema, calculou-se uma taxa de recirculação do ar de $82 \%$.

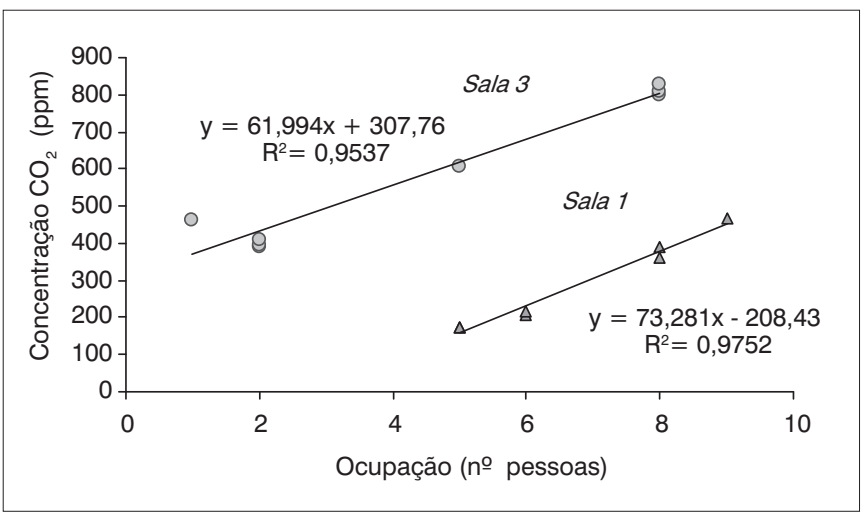

Figura 1 - Relação entre a concentração de $\mathrm{CO}_{2}$ e o grau de ocupação das salas de cirurgia
Considerando esse dado e as vazões efetivamente medidas nas salas de 3.120 e $2.755 \mathrm{~m}^{3} \cdot \mathrm{h}^{-1}$, respectivamente, verificou-se que as taxas de renovação do ar para uma ocupação de dez pessoas em cada sala de cirurgia (ocupação máxima observada durante as amostragens) seriam de 57,0 e 50,4 $\mathrm{m}^{3} \cdot \mathrm{h}^{-1}$. pessoa ${ }^{-1}$, valores superiores ao mínimo recomendado pela RE 9 , de $27 \mathrm{~m}^{3} \cdot \mathrm{h}^{-1}$. pessoa $^{-1}$. Calculou-se, também, a ocupação máxima de cada sala de cirurgia obedecendo a este requisito. Observou-se que, ainda com 21 e 29 pessoas nas salas 1 e 3 , respectivamente, seria obedecida a legislação.

A partir das dimensões dessas salas, calcularam-se 44 e 47 trocas de ar por hora, respectivamente. Esses números foram superiores àqueles recomendados pelo Centro de Controle de Doenças (CENTER FOR DISEASE CONTROL, 1999) de 15 trocas de ar por hora com $20 \%$ de renovação do ar. Este resultado confirmou que o sistema de ar condicionado dos ambientes estudados se encontra operando de maneira apropriada em relação à sua vazão. O correto grau de troca do ar de ambientes hospitalares é fundamental para garantir que não ocorra acúmulo de possíveis contaminantes do ar de interiores, que poderiam prejudicar não somente a saúde do paciente, mas também da equipe médica.

A Tabela 2 apresenta os resultados obtidos para a concentração de bioaerosóis, coletados com dois tipos de meio de cultura e contabilizados em dois grupos (fungos filamentosos e colônias de aparência cremosa - bactérias ou leveduras). Pode-se observar também a relação I/E que exprime a razão entre a concentração de fungos no ambiente de interiores e no ponto externo.

A concentração de fungos filamentosos observada é substancialmente superior a valores encontrados em outros países. Um trabalho realizado em um hospital na França utilizou um amostrador diferente daquele usado neste trabalho, mas usou o mesmo meio de cultura (Sabouraud), obtendo <10 UFC. $\mathrm{m}^{-3}$ para fungos filamentosos em todas as suas amostras (SAUTOUR et al, 2009).

Foi possível observar uma variação nas concentrações de bioaerosóis em todos os ambientes, embora uma tendência clara não seja observada. Em termos gerais, percebe-se um aumento nas concentrações de bioaerosóis no decorrer do dia. Em nenhum ambiente, a

Tabela 2 - Concentração média de bioaerosóis na unidade de terapia intensiva (UTI) adulto, UTI neonatal (UTN) e centro cirúrgico (CC) $\left(\right.$ UFC. $\left.\mathrm{m}^{-3}\right)$

\begin{tabular}{|c|c|c|c|c|c|}
\hline Local & Período & $\begin{array}{l}\text { Fungos filamentosos } \\
\text { (ASD)* }\end{array}$ & I/E fungos ASD & $\begin{array}{l}\text { Bactérias } \\
\text { (ASC)* }\end{array}$ & $\begin{array}{c}\text { Total } \\
\text { (ASC+ASD) }\end{array}$ \\
\hline UTI & Manhã & 86 & 0,1 & 843 & 929 \\
\hline UTI & Tarde & 191 & 0,3 & 162 & 353 \\
\hline UTN & Manhã & 62 & 0,1 & 54 & 116 \\
\hline UTN & Tarde & 351 & 0,6 & 337 & 688 \\
\hline CC - Sala 1 & Integral & 133 & 0,2 & 38 & 171 \\
\hline CC - Sala 3 & Integral & 160 & 0,3 & 189 & 349 \\
\hline$P E^{\star \star}$ & - & 591 & - & - & - \\
\hline Padrões RE n. 9 & & $<750$ & 1.5 & - & - \\
\hline
\end{tabular}

(*) ASD: amostras coletadas com ágar Sabouraud Dextrose, contando-se somente os fungos filamentosos; ASC: amostras coletadas com ágar Sangue de Carneiro, contando-se somente as colônias de bactérias.

(**) PE: média dos resultados obtidos no ponto externo 
concentração média de fungos filamentosos coletados em ASD ultrapassou o valor máximo recomendado pela resolução RE 9 da Anvisa, de 750 UFC.m ${ }^{-3}$ (BRASIL, 2003). O valor máximo no ambiente interno foi observado na UTI neonatal, com 351 UFC.m ${ }^{-3}$. Nem mesmo no ambiente externo atingiu-se o valor máximo estabelecido. Entretanto, cabe salientar que a consulta pública no 109 (que ainda não está em vigor), propõe o valor máximo de somente 200 UFC.m ${ }^{-3}$ para a contagem total de bactérias e fungos. Considerando-se esse valor, apenas a UTI neonatal, no período da manhã, e a sala 1 do centro cirúrgico estariam dentro dos padrões recomendados.

Percebe-se, ainda, que tanto na UTI quanto na UTN, a concentração de fungos foi maior no período da tarde. Entretanto, a concentração de bactérias na UTI, foi maior no período da manhã. Neste caso, de forma contraditória, o valor obtido para a alta concentração de bactérias no ar não estava acompanhada de uma alta concentração de fungos ou de uma alta taxa de ocupação no local.

A concentração média horária de fungos filamentosos e de bactérias, bem como o número de ocupantes no ambiente medidos nas salas de cirurgia 1 e 3 do centro cirúrgico são apresentadas nas Figuras 2 e 3 , respectivamente.

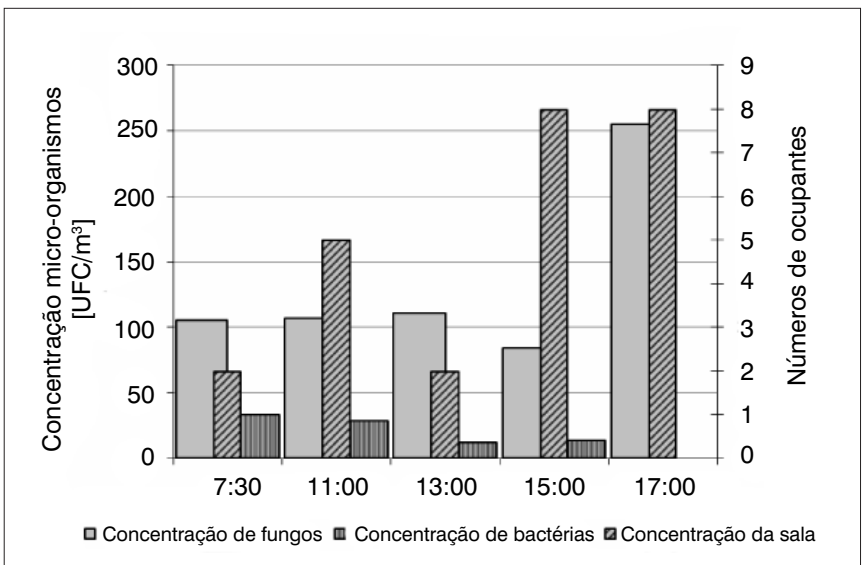

Figura 2 - Concentração horária de fungos e bactérias e ocupação da sala 1 do centro cirúrgico

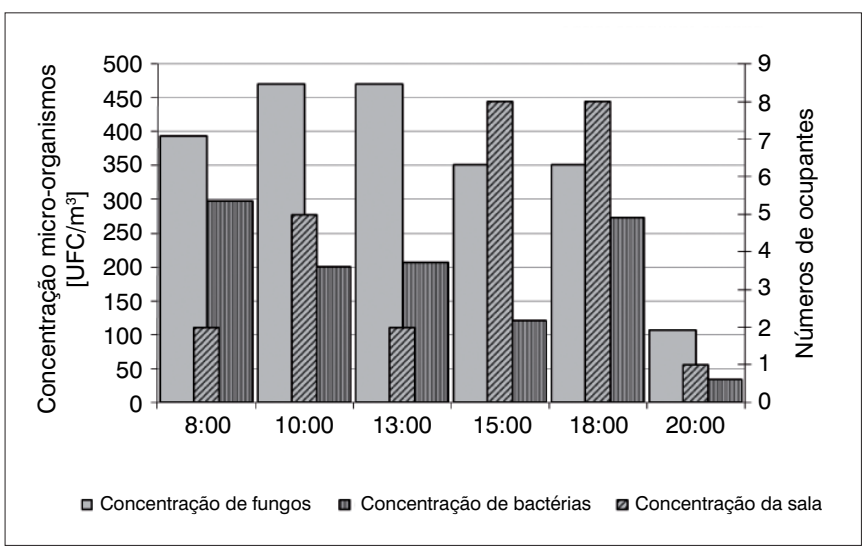

Figura 3 - Concentração horária de fungos e bactérias e ocupação da sala 3 do centro cirúrgico
Das 33 amostras de ar obtidas pela amostragem dinâmica, com os meios de cultura ASD e ASC, foi possível isolar 59 fungos filamentosos. Dentre eles, 49 foram identificados em dez diferentes gêneros. Os gêneros mais frequentes foram Aspergillus e Penicillium, com 15 e 14 isolados, respectivamente, seguidos por Cladosporium (oito isolados), Trichoderma (quatro), Acremonium e Fusarium (dois). Os demais gêneros (Circinella, Curvularia, Verticillium e Pithomyces) foram identificados em um isolado cada. Das 59 colônias de fungos filamentosos isoladas, apenas três foram retiradas de amostras coletadas com ASC e todas foram identificadas como pertencentes ao gênero Aspergillus.

Foram isoladas 28 colônias de aparência cremosa. Destas, 14 foram retiradas de amostras coletadas em meio ASC e nove foram retiradas de amostras coletadas em meio ASD. Percebeu-se uma grande frequência de possíveis integrantes do gênero Staphylococcus (42,9\% dos isolados). Não foram observadas bactérias $\alpha$-hemolíticas dentre os isolados. Entre os cinco isolados $\beta$-hemolíticos, observaram-se estafilococos e bacilos, tanto gram-positivos como gram-negativos.

Embora os meios de cultura apresentem certo grau de seletividade e favoreçam o crescimento de fungos e bactérias, respectivamente, observou-se um crescimento elevado de colônias de aparência cremosa no ASD (bactérias e leveduras). Já nas 31 placas coletadas com ASC, quatro apresentaram o crescimento de fungos, correspondendo a $12,9 \%$ das amostras

Foi observada uma grande frequência de fungos do gênero Aspergillus nos hospitais e edifícios públicos avaliados por outros autores (KIM; KIM, 2007; NUNES, 2005; PORTNOY; FLAPPAN; BARNES, 2001). Portnoy, Flappan e Barnes (2001) também detectaram representantes do gênero Penicillium como o segundo grupo mais frequente, seguidos pelos do gênero Cladosporium. Zorman e Jersek (2008) encontraram fungos do gênero Penicillium com maior frequência.

Dentre os isolados de Aspergillus, observou-se uma grande diversidade morfológica, considerando-se a cor das colônias e também o formato e tamanho dos conidióforos, o que pode indicar uma grande diversidade de espécies desse gênero. Dentre os isolados do gênero Penicillium, a variação não foi tão grande, já que os conidióforos apresentavam formatos similares na maioria dos isolados, e a coloração da colônia também variou pouco. Este gênero também foi encontrado com frequência dominante em edifícios de uso público na Coreia e em hospitais do Rio de Janeiro (KIM; KIM, 2007; NUNES, 2005). Mangram et al (1999) associa infecções do sítio cirúrgico predominantemente a estafilococos. Coincidentemente, os relatórios mensais da comissão de controle de infecção hospitalar deste mesmo hospital, de novembro de 2007 a janeiro de 2008, mostraram 18 casos de infecção hospitalar por Staphylococcus spp.

A relação entre a concentração de fungos filamentosos observada nos ambientes internos e no ambiente externo (I/E) encontrava-se muito abaixo do valor máximo recomendado pela resolução RE 9 da Anvisa, que é de 1,5, a concentração de fungos filamentosos no ar de 
interiores foi substancialmente inferior à concentração do ambiente externo. Kim e Kim (2007) também obtiveram resultados similares para a relação I/E em edifícios públicos na Coreia.

Em relação à concentração de micro-organismos no ar, não foi possível confirmar se o valor máximo recomendado pela $\mathrm{CP} \mathrm{n}^{\circ}$ 109, de 200 UFC.m ${ }^{-3}$ para a contagem total de micro-organismos é um bom parâmetro para ambientes como UTI e salas de cirurgia. Entretanto, em relação à resolução RE 9 , é possível afirmar que um máximo de 750 UFC. m $^{-3}$ para ambientes internos aparenta ser uma exigência de grande tolerância.

Em relação à legislação nacional sobre a qualidade do ar em ambientes internos, é possível fazer as seguintes considerações:

- Recomenda-se que a concentração de $\mathrm{CO}_{2}$ seja contemplada na resolução a ser estabelecida a partir da consulta pública CP n. 109, pois a concentração desse gás é um parâmetro indicador da taxa de renovação do ar, que considera o grau de ocupação do ambiente;

- A partir dos resultados obtidos neste trabalho, há alguns pontos a serem levados em consideração sobre a seguinte frase da resolução RE n. 9 da Anvisa:

"O valor máximo recomendável (VMR), para a contaminação microbiológica deve ser $\leq 750$ UFC. $m^{-3}$ de fungos, para relação I/E $\leq$ 1,5, onde I é a quantidade de fungos no ambiente interior e Eé a quantidade de fungos no ambiente exterior" (BRASIL, 2003).

1) Como se observou um crescimento numeroso de colônias de bactérias e leveduras no meio de cultura ASD (seletivo para fungos), recomenda-se que esta frase seja alterada de modo a esclarecer se a contagem deve ser de fungos filamentosos somente ou se as leveduras devem ser incluídas;

2) Sabendo-se que a microbiota do ar é transportada pelo material particulado, entende-se que a concentração de micro-organismos seja superior nos ambientes externos, fato confirmado nos resultados deste trabalho. Um resultado superior a 1,0 para esta relação permitiria assumir que há acúmulo de contaminantes biológicos no ambiente interno. Desta forma, critica-se a relação $\mathrm{I} / \mathrm{E} \leq 1,5$ que indica que o ambiente interno pode ter uma concentração de microorganismos 50\% maior que o ambiente externo. Sugere-se que, especialmente no ambiente hospitalar, essa relação seja reduzida para $\mathrm{I} / \mathrm{E}<1,0$;
3) O tempo de incubação de fungos filamentosos não deve ser fixado em sete dias para a contagem das colônias, como é especificado na resolução RE 9 pois, em alguns casos, a superfície do meio de cultura na placa de Petri pode ser coberta pelo micélio em períodos mais curtos de tempo, o que impossibilita a contagem das colônias. Para tanto, recomenda-se que a resolução especifique o monitoramento diário das placas com lupa até que o número de colônias se estabilize, o que ocorre em prazo menor do que sete dias;

4) É possível afirmar que um máximo de 750 UFC.m ${ }^{-3}$ para ambientes internos é uma exigência de grande tolerância. Sugere-se sua alteração para um valor menor, já que em nenhuma amostra analisada, mesmo em ambiente externo, obteve-se resultado desta ordem de grandeza.

\section{Conclusões}

Neste trabalho, avaliou-se a qualidade do ar de três categorias de ambientes hospitalares: UTI neonatal, UTI adulto e centro cirúrgico de um hospital localizado em Florianópolis (SC). A partir de uma análise dos resultados obtidos, é possível concluir, especificamente, que a concentração de $\mathrm{CO}_{2}$ nas salas de cirurgia apresentou uma relação linear direta com o grau de ocupação dos ambientes, evidenciando que os sistemas de ar condicionado são projetados para atender a um determinado grau de ocupação no ambiente.

A concentração de fungos filamentosos no ar é o parâmetro microbiológico que representa melhor o nível de ocupação dos ambientes, confirmando seu uso como indicador da qualidade do ar de interiores, sendo Aspergillus e Penicillium os gêneros de fungos mais frequentes. O gênero mais comum dentre as bactérias foi Staphylococcus. Também se observou que a qualidade do ar das salas de cirurgia não se deteriora com o passar do dia.

A realização deste trabalho também tornou possível uma análise crítica da legislação brasileira atual específica para ambientes internos, levantando a necessidade de se especificarem parâmetros para ambientes hospitalares, que devem ser enquadrados em uma categoria especial para a qualidade do ar de interiores por abrigarem uma grande quantidade de pessoas com deficiências no sistema imunológico. Assim, conclui-se que padrões para a qualidade do ar de interiores devem ser regulamentados especificamente para ambientes hospitalares e unidades de saúde. Esses padrões devem ser mais restritivos do que aqueles descritos na resolução RE 9 da Anvisa.

\section{Referências}

ALEXOPOULOS, C.J.; MIMS, C.W.; BLACKWELL, M. Introductory mycology. New York: John Wily \& Sons, Inc., 1996.

BARBETTA, P.A.; REIS, M.M.; BORNIA, A.C. Estatística para cursos de engenharia e informática. $2^{a}$ ed. São Paulo: Atlas, 2008.
BENNY, G.L. Zygomycetes. [On-line]. Disponível em: http://www. zygomycetes.org. Acessado em: 17 jul. 2009.

BRASIL. Ministério da Saúde. Agência Nacional de Vigilância Sanitária. Resolução no 9, 2003. 
BRICKUS, L.S.; AQUINO NETO, F.R. A qualidade do ar de interiores e a química. Química Nova, v. 22, n. 1, p. 56-74, 1999.

CENTER FOR DISEASE CONTROL (CDC). Guideline for prevention of surgical site infection. Infection Control and Hospital Epidemiology, v. 20, n. 4, p. 247-277, 1999.

DASCALAKI, E.G. et al. Indoor environmental quality in Hellenic hospital operating rooms. Energy and Buildings, v. 41, n. 5, p. 551-560, 2009.

GIODA, A. Poluição atmosférica e de interiores: influência mútua e seus reflexos na saúde. 212 f. Tese (Doutorado Química Orgânica - Instituto de Química) - Universidade Federal do Rio de Janeiro, Rio de Janeiro, 2003.

GIODA, A.; AQUINO NETO, F.R. Considerações sobre estudos de ambientes industriais e não-industriais no Brasil: uma abordagem comparativa. Cadernos de Saúde Pública, v. 19, n. 5, p. 1389-1397, 2003.

HELLGREN, U.M.; REIJULA, K. Indoor-air-related complaints and symptoms among hospital workers. Scandinavian Journal of Work, Environment \& Health (Supplements), v. 2, p. 47-49, 2006.

HO, S.H.; ROSARIO, L.; RAHMAN, M.M. Three-dimensional analysis for hospital operating room thermal comfort and contaminant removal. Applied Thermal Engineering, v. 29, n. 10, p. 2080-2092, 2009.

JONES, A.P. Indoor air quality and health. Atmospheric Environment, v. 33, n. 1, p. 4535-4564, 1999.

KENDRICK, B. The fifth kingdom. Newburyport: Focus Publishing, 2000

The whole fungus: proceedings of the Second International Mycological Conference. In: II INTERNATIONAL MYCOLOGICAL CONFERENCE, Calgary: National Museum of Natural Sciences, National Museum of Canada, The Kananaskis Foundation, 1979.

KIM, K.Y.; KIM, C.N. Airborne microbiological characteristics in public buildings of Korea. Building and Environment, v. 5, n. 42, p. 8, 2007.

KONEMAN, E.W. etal. Color atlas and textbook of diagnostic microbiology. 5. ed, Philadelphia: Lippincott-Rave, 1997.

KWOC, A.G. Thermal comfort: concepts and guidelines. In: SPENGLER, J.D.; SAMET, J.M.; MCCARTHY, J.F. Indoor air quality handbook. New York: McGraw-Hill, p. 15.3-15.4, 2004.

LEE, H.; AWBI, H.B. Effect of internal partitioning on indoor air quality of rooms with mixing ventilation: basic study. Building and Environment, v. 39, n. 2, p. 27-41, 2004.

MANGRAM, A.J. et al. Guideline for prevention of surgical site infection. Infection Control and Hospital Epidemiology, v. 20, n. 4, p. 247, 1999.

MOBIN, M.; SALMITO, M.D.A. Microbiotal fúngica dos condicionadores de ar nas unidades de terapia intensiva de Teresina, PI. Revista da
Sociedade Brasileira de Medicina Tropical, v. 39, n. 6, p. 3, 2006

NORDSTROM, K.; NORBACK, D.; AKSELSSON, R. Influence of indoor air-quality and personal factors on the sick building syndrome (SBS) in Swedish geriatric hospitals. Occupational and Environmental Medicine, v. 52 , n. 3, p. 170-176, 1995

NUNES, Z.G. Estudo da qualidade microbiológica do ar de ambientes internos climatizados. 163 f. Tese (Doutorado em Vigilância Sanitária) - Instituto Nacional de Controle de Qualidade em Saúde, Fundação Oswaldo Cruz, Rio de Janeiro, 2005.

PASQUARELLA, C.; PITZURRA, O.; SAVINO, A. The index of microbial air contamination. Journal of hospital infection, v. 46, n. 4, p. 15, 2000

PORTNOY, J.M., FLAPPAN, S.; BARNES, C.S. A procedure for evaluation of the indoor environment. Aerobiologia, v. 17, n. 1, p. 5, 2001.

SAUTOUR, M. et al. A prospective survey of air and surface fungal contamination in a medical mycology laboratory at a tertiary care university hospital. American Journal of Infection Control, v. 37, n. 3, p. 189-194, 2009.

SILVA-FILHO, G.N.; OLIVEIRA, V.L. Microbiologia: manual de aulas práticas. Florianópolis: UFSC, 2007.

SILVEIRA, V. D. Micologia. 5. ed. Rio de Janeiro: Âmbito Cultural, 1995.

SPENGLER, J.D. Indoor air quality handbook. 1 ed. New York: McGrawHill, 2004. v. 1

SRIKANTH, P.; SUDHARSANAM, S.; STEINBERG, R. Bio-aerosols in indoor environment: Composition, health effects and analysis. Indian Journal of Medical Microbiology, v. 26, n. 4, p. 302-312, 2008.

TURIEL, I. et al. The effects of reduced ventilation on indoor air quality in an office building. Atmospheric Environment, v. 17, n. 1, p. 51-64, 1983.

UNIVERSITY OF ADELAIDE (UA). Mycology Online. Disponível em: http:// www.mycology.adelaide.edu.au/. Acesso em: 17 jul. 2009.

WANG, S.; ANG, H.M.; TADE, M.O. Volatile organic compounds in indoor environment and photocatalytic oxidation: state of the art. Environment International, v. 33, n. 5, p. 694-705, 2007.

WEBSTER, J. Introduction to fungi. 2. ed. Oxford: Cambridge University Press, 1985

WORLD HEALTH ORGANIZATION (WHO). Programmes and projects: indoor air pollution. 2008. Disponível em: http://www.who.int/indoorair/ en. Acessado em 17 jan. 2008.

ZHANG, Y. Indoor air quality engineering. 1. ed. Boca Raton: CRC Press, 2004

ZORMAN, T.; JERSEK, B. Assessment of bioaerosol concentrations in different indoor environments. Indoor and Built Environment, v. 17, n. 2 , p. $155-163,2008$ 